\title{
New Approach for Optimizing Control of Switched Reluctance Generator
}

\author{
R. Rebbah, A. Bentounsi and H. Benalla
}

\begin{abstract}
This paper presents a new switching approach that determines the optimal control of the Switched Reluctance Generator (SRG) for accomplishing maximum energy conversions. The proposed method is based on the novel concept of "ideal base speed flux/current curve" that optimizes the conduction angles in the mode of single-pulse and Chopping Current Control (CCC) operations. To validate the proposed control technique, simulation results are provided. The practicality of the controller is illustrated by a variable speed wind application of a 6/4 SRG.
\end{abstract}

Index Terms - Optimal control, conduction angles, Switched Reluctance Generator, optimization, variable speed, wind power.

\section{INTRODUCTION}

In the context of sustained development, electric power generation using non-conventional sources is receiving an increasing attention. Among the alternative resources to fossils, wind energy occupies today a place of choice. Variable speed power generation for a wind turbine is attractive, because maximum efficiency can be achieved at all wind velocities. In this field, the switched reluctance machines compete with the classical ones due to their multiple advantages: simplicity and robustness of the structures, high performances and reduced cost, which allows them to have various applications over a large speed range, for motoring and generating modes. However, the drawbacks of these machines are in particular voltage, current and torque ripples, but also the power electronics requirements [1-2].

In order to optimize the power conversion, a greater attention was focused to the Switched Reluctance Generator (SRG) control; the turn-on and the conduction angles together are the key element for optimal excitation. The conventional control method that advances the turn-on angle as the speed increase is not sufficient to produce optimum performance [3].

This paper investigates the problem of performance optimization of the SRG at variable speed. The proposed method is based on the optimization of conduction angle to approach the "ideal base speed flux/current curve" that maximizes energy conversion in both cases of single-pulse and Chopping Current Control (CCC).

Manuscript received September 29, 2009. This work was supported by the Electrical Engineering laboratory of mentouri university (LEC), Constantine, Algeria.

R. Rebbah is with the dept. of Electrical Engineering, LEC, Constantine, Alegria. (E-mail: redjem_rebbah@yahoo.fr).
For this study, we used a three-phase 6/4 SRG represented in Fig.1. There are no windings and no magnets in the rotor; there is only a concentric coil in each stator pole. The parameters of the studied generator are given in Table I.

For determining the electromagnetic characteristics of the machine connected to the converter, we solve the Poisson's equation governing the problem by the finite elements method (FEM). The implementation was carried out under the software package Flux2D [4], a user-friendly software which allowed us to draw the equal flux lines from which we plotted the magnetic flux vs. phase currents (Fig. 2).

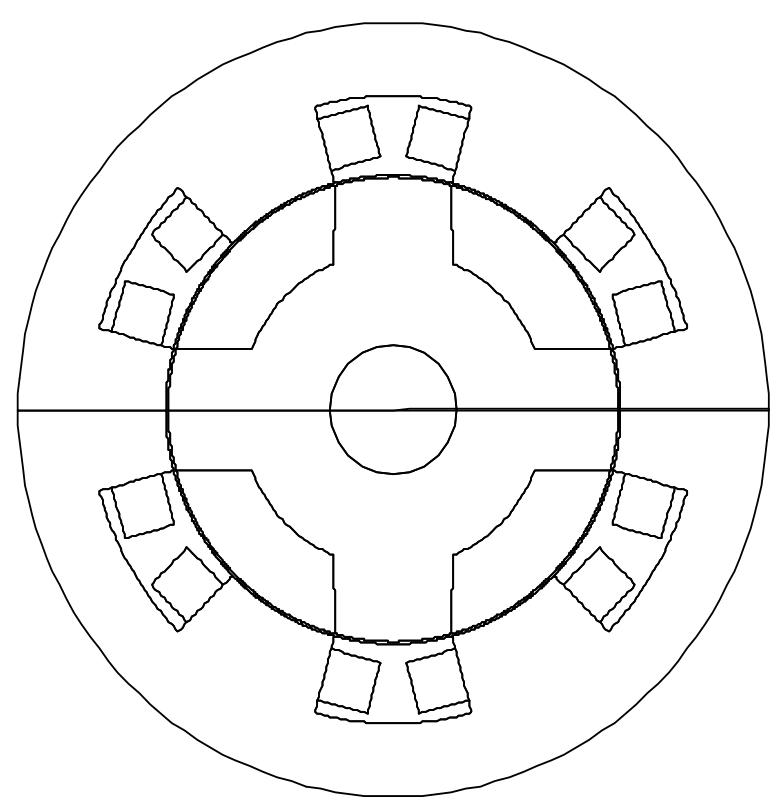

Fig.1. Diagram of the studied three phase 6/4 SRG

TABLE I

PARAMETERS OF THE STUDIED 6/4 SRG

\begin{tabular}{|l|c|}
\hline \multicolumn{1}{|c|}{ Quantity } & Value \\
\hline Stack length & \\
Outer diameter & $150 \mathrm{~mm}$ \\
Rotor diameter & $250 \mathrm{~mm}$ \\
Shaft diameter & $150 \mathrm{~mm}$ \\
Air-gap length & $42 \mathrm{~mm}$ \\
Height of stator teeth & $0.8 \mathrm{~mm}$ \\
Height of rotor teeth & $25.6 \mathrm{~mm}$ \\
Stator yoke thickness & $28 \mathrm{~mm}$ \\
Aligned inductance & $23.6 \mathrm{~mm}$ \\
Unaligned inductance & $2.2 \mathrm{mH}$ \\
& $0.2 \mathrm{mH}$ \\
& \\
\hline
\end{tabular}




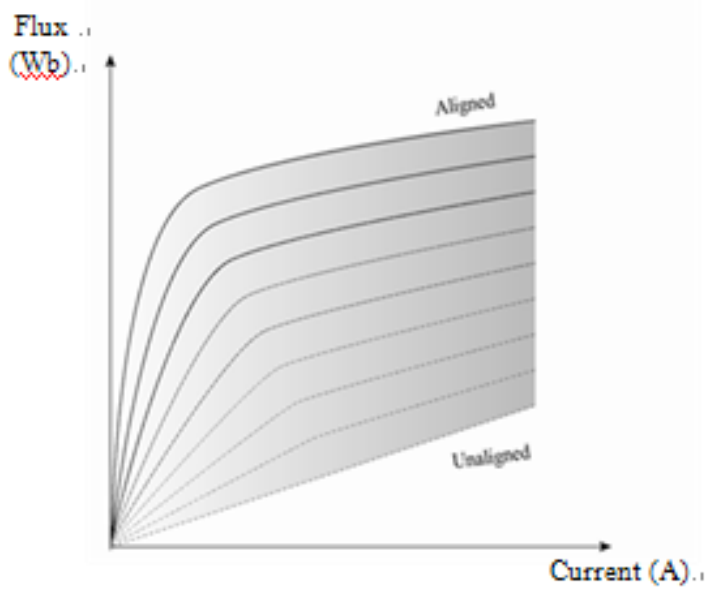

Fig. 2. Magnetization curves.

\section{ENERGY CONVERSION SYSTEM}

The electro-mechanic conversion system of energy is constituted by SRG, power converter, controller, position sensor and so on. The topology of its power inverter is a three-phase asymmetric half bridge where one phase is represented in Fig. 3. The rotor of SRG is driven by a prime mover. The controller can create certain control signals according to the position information of the rotor. The control signals can drive the switches in power inverter to implement excitation and electric power generation.

There are two controllable switches ( $\mathrm{Tl}, \mathrm{T} 2)$ and two diodes (Dl, D2) in each phase. When both $\mathrm{Tl}$ and $\mathrm{T} 2$ are turned on, the winding is excited; the system absorbs energy from the prime motor and the exciting source. When both $\mathrm{Tl}$ and $\mathrm{T} 2$ are turned off, the winding releases energy through $\mathrm{Dl}$ and D2, the system provides electric energy to the load.

From the previous magnetic characteristics (Fig. 2) plotted under Flux2D software, we can deduce the inductance curves vs. rotor position at different excitations. Fig. 4 shows the relationship between the idealized inductance profile and phase currents for generating at single voltage pulse and PWM voltage, above base speed at which the phase currents are nominally constant without need for regulation. It also represents the speed where the back-emf $E$ balances the source voltage $V$ and resistive drop $R I$ [5].

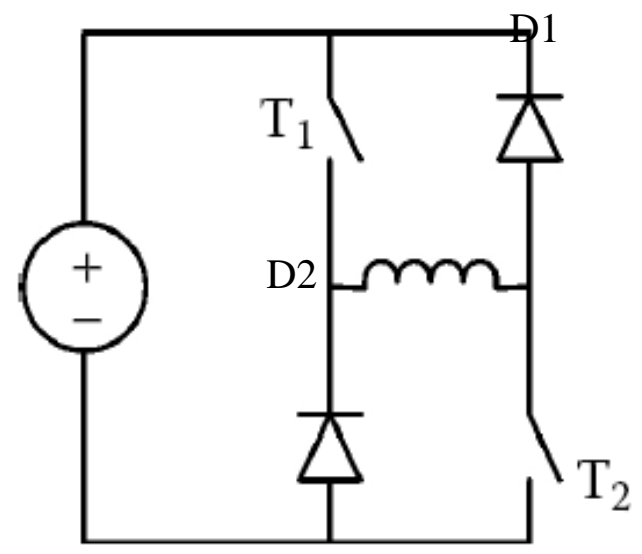

Fig. 3. One phase of the power converter.

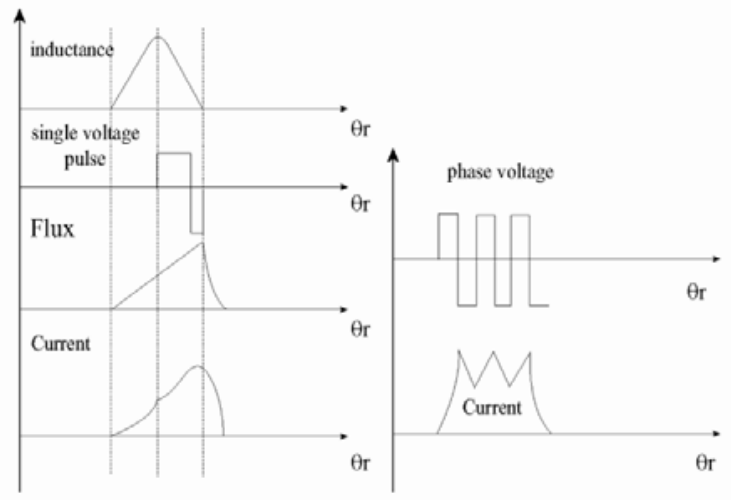

(a)

(b)

Fig. 4. Waveforms of (a) high-speed single voltage pulse and (b) low-speed current chopping control (CCC) operations.

During generation, the SRG produces negative torque that tends to oppose rotation, thereby extracting energy from the prime mover. If the phase is excited as the rotor poles move through the aligned position, the rotor experiences torque opposing rotation consistent with generator operation. The stored magnetic energy $\left(W_{e}\right)$ or co-energy $\left(W_{c}\right)$ varies with rotor position to produce the electromagnetic torque:

$$
T_{e}=\left(\frac{\partial W_{e}\left(i, \theta_{r}\right)}{\partial \theta_{r}}\right)_{i=\text { const }}=\left(\frac{\partial W_{c}\left(\psi, \theta_{r}\right)}{\partial \theta_{r}}\right)_{\psi=\text { const }}
$$

which is produced through magnetic anisotropy. In linear mode, the magnetic flux is:

$$
\psi=L\left(\theta_{r}\right) i
$$

Thus,

$$
W_{e}=W_{c}=\frac{1}{2} L\left(\theta_{r}\right) i^{2}
$$

If, moreover, we suppose that the phase inductance varies linearly with rotor position, from its maximum (aligned position) to its minimum (unaligned position) value, for constant current pulse, the torque is constant over the active rotor position range, according to the following expression:

$$
T_{e}=\frac{1}{2} i^{2} \frac{d L\left(\theta_{r}\right)}{d \theta_{r}}=\text { const }
$$

$\bullet$

$$
\frac{d L\left(\theta_{r}\right)}{d \theta_{r}}>0
$$

$$
\begin{array}{lll} 
& \text { For } & \multicolumn{2}{c}{\text { generator }} \\
\text { operation: } & \frac{d L\left(\theta_{r}\right)}{d \theta_{r}}<0 \quad \text { (4b) }
\end{array}
$$

It is clear that the polarity of the current does not influence the sign of the torque.

The expression of the average torque per phase is: 


$$
T_{a v}=\frac{m N_{r} W_{\text {mec }}}{2 \pi}
$$

The energy per cycle is deduced from the area between the aligned and unaligned flux vs. current curves represented

(Fig.

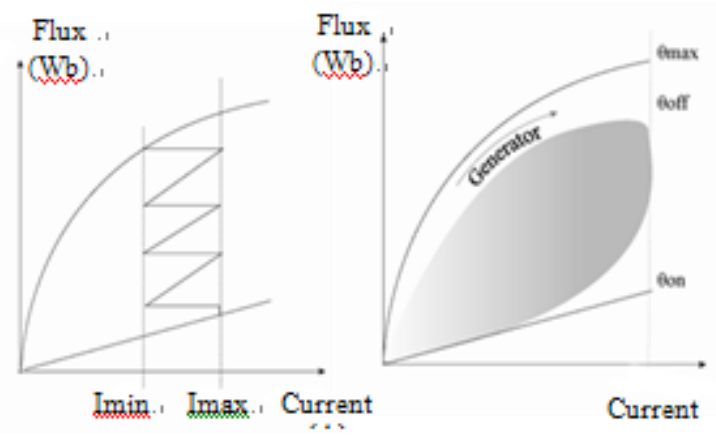

(a)

Fig. 5. Aligned and unaligned curves at (a) CCC and (b) single pulse mode.

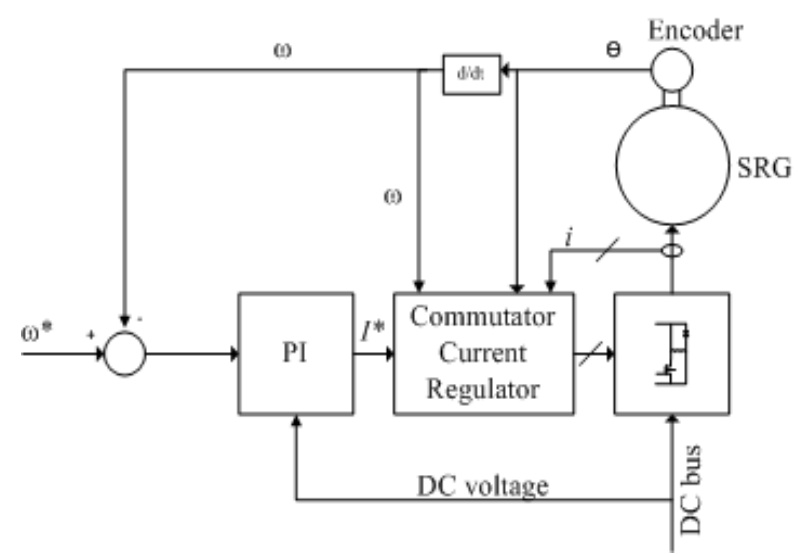

Fig. 6. Controllers for regulating SRG speed.

\section{SPEED CONTROL OF SRG SYSTEM}

For the strategy called "torque demand" recognized as having a weak dynamic response for variable winds, there are several publications [6-16]. As an alternative to the torque control strategy, a speed control strategy represented in Fig. 6 has been reported in [6].

This strategy has more variation in the output power and also the fast variation of the electrical torque can produce for example more fatigue in the gear box and drive train of the wind turbine. This problem can be reduced with a good design of the controller [17].

The outer loop is usually concerned with regulating the speed of the SRG. An application such as wind energy would focus on regulating the speed of the SRG relative to that of the wind stream in order to force peak aerodynamic efficiency [5].

\section{SimULATION RESULTS}

\section{A. Current waveforms}

The voltage equation per phase of the SRG is given by:

$$
V=R I+L \frac{d i}{d t}+K \omega
$$

where $V$ is the applied voltage, $I$ is the current, $R$ is the resistance per phase, $L$ is the inductance per phase, $\omega=\frac{d \theta}{d t}$ is the angular speed of the rotor and $E=\omega K$ is the back EMF with the coefficient:

$$
K=i \frac{d L}{d \theta}<0
$$

For simplicity, we neglect the stator resistance $(R=0)$. The value of the voltage is: excitation phase by $\mathrm{T}_{1,2}$ switches

$$
V=+V d c \text { during }
$$

-

$$
V=-V d c \text { during }
$$
generating phase by $\mathrm{D}_{1,2}$ free-wheeling diodes

where $V d c$ is the voltage of the DC bus.

The corresponding current waveforms are idealized (Fig. 7).

Fig. 8 shows the simulated characteristics of flux, current, torque and speed by using MATLAB software; the model selected is the 6/4 SRM block proposed by T.J.E. Miller [9]. Fig. 9, 10 and 11 show the current curves corresponding respectively to three cases of the speed $n$ compared to the base speed $n b$.

- In case $1(n>n b)$ : after T1 and T2 are turned off (when excitation phase is finished) the current still increases. As $\mathrm{V}<0$ and $\mathrm{E}<0$, the current increase is due to the fact that is the EMF is greater than the supply voltage (magnetization). This case is typical for high speeds, when the torque is smaller (Fig. 9).

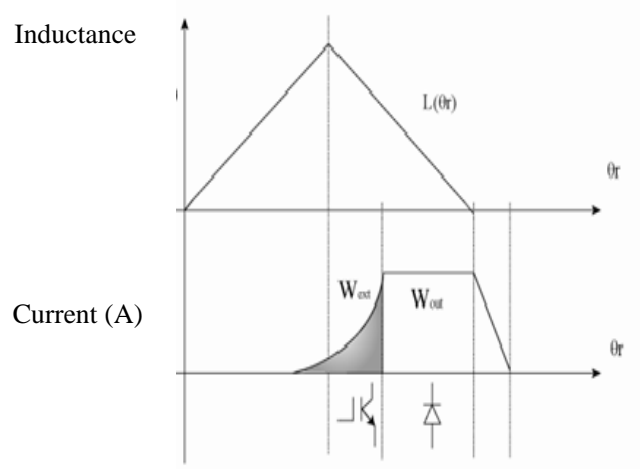

Fig. 7. Waveforms of inductance and phase current.

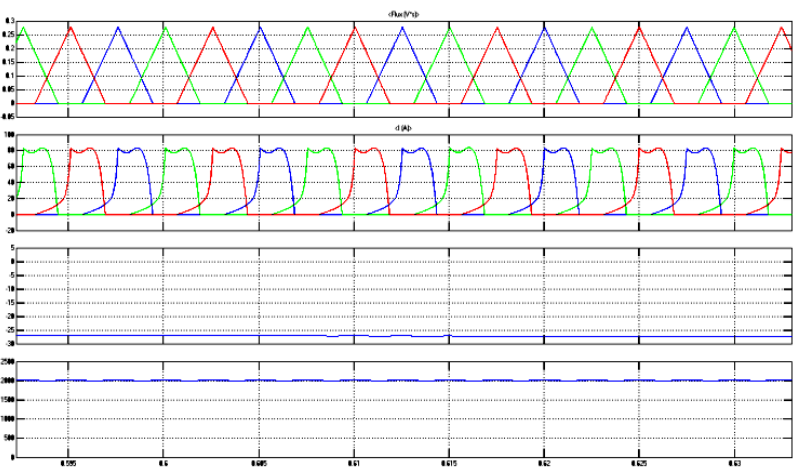

Fig. 8. Simulations of flux, current, torque and speed. 


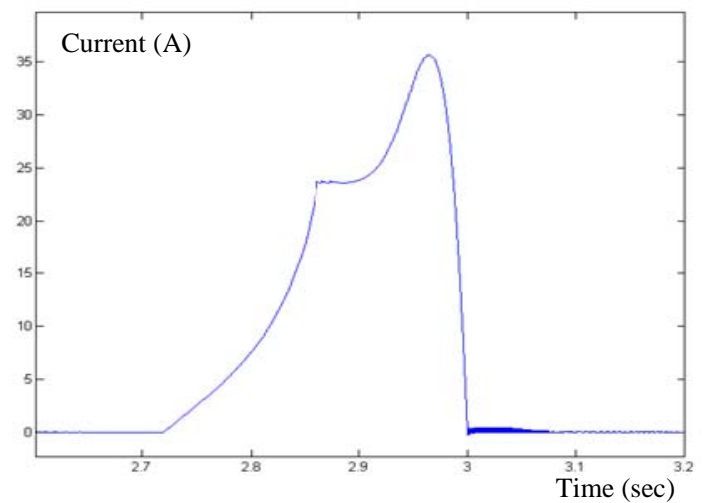

Fig. 9. Current at $n>n b$ (case 1 )

- For case $2(n=n b)$ : it happens at turn-off angle $\theta_{\text {off }}$ where $|E|=\left|V_{d c}\right|$ and thus, from Equation (5), $\frac{d i}{d t}=0$. Consequently, the current remains constant (Fig. 10) until the inductance reaches its minimum at energy cycle (2). As shown in Fig. 13.a, case (2) produces the largest torqueenergy cycle and, thus, seems more effective in energy conversion.

- In case $3(n<n b)$ : in (Fig. 11), the maximum current is reached at $\theta_{\text {off }}$ and after that, the current decreases steadily, because $|E|<\left|V_{d c}\right|$, which corresponds to low speeds. A smaller torque area is typical for case (3).

\section{B. Energy conversion cycles}

The area enclosed by each loop represents the energy converted from mechanical to electrical form per electrical phase cycle of each phase. This loop is obtained for each phase cycle (stroke) by drawing the graph of the linkage flux versus phase current (Fig. 12). Six loops of energy conversion for the studied 6/4 SRG at six different speeds are shown in (Fig. 13a) for single-pulse mode and (Fig. 13b) for CCC mode.

At low speed we always have control through actively chopping the current, the windings current is limited by chopping control during increasing inductance (Fig. 4).

Above base speed the machine starts operating in singlepulse mode and in generator mode the phase current can continue to increase even after the excitation turned off [3].

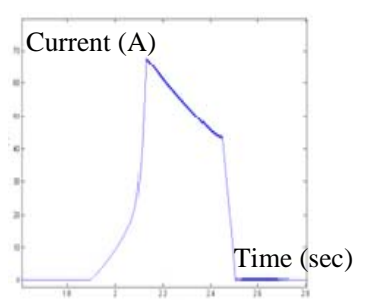

Fig. 10. Current at $n=n b$ (Case 2)

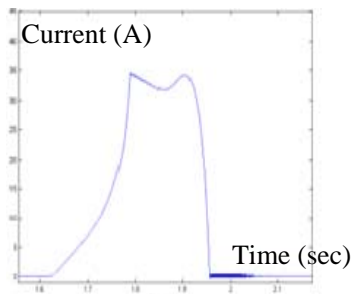

Fig. 11. Current at $n<n b$ (Case 3)
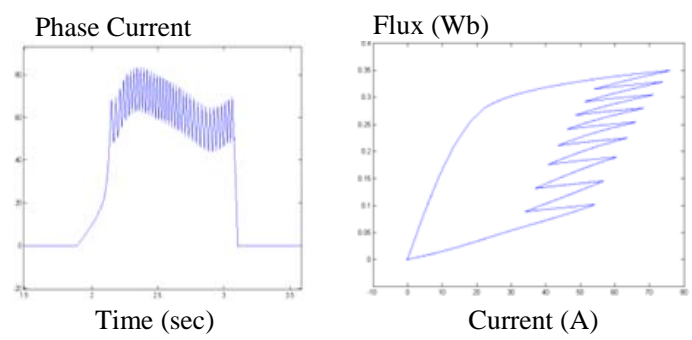

Fig. 12. Flux vs. current and Current vs. time at low-speed for CCC mode

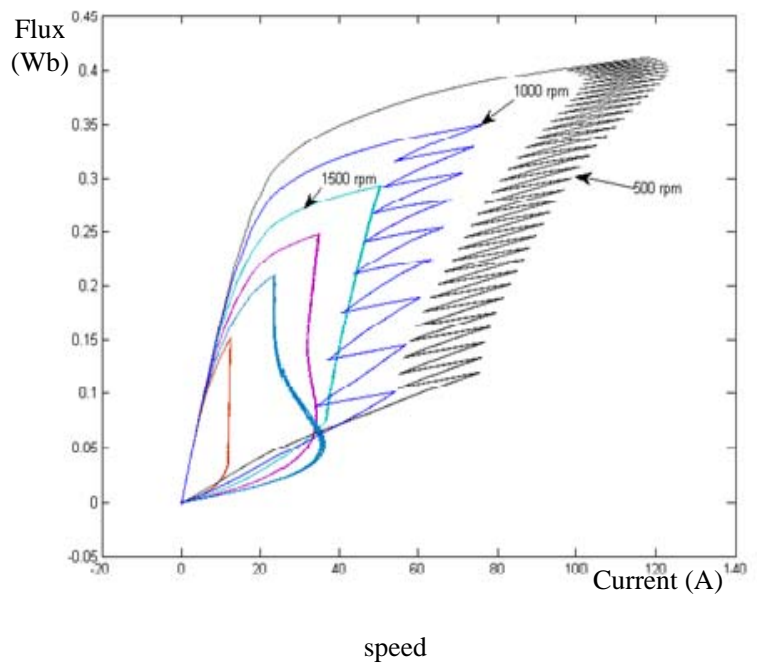

Fig. 13.b Simulation of current at low-speed (CCC)

\section{OPTIMIZATION}

The optimization procedure achieved under MATLAB software is applied to the control of the SRG with the following parameters constraints (Table II). Lower and higher limits of each variable define the search region of the previous loop (fig.13). After specifying limits, the variable $x$ of the objective function (7) represents a vector of angle values $\theta_{\text {on }}, \theta_{\text {off }}$. Then, the algorithm represented in Fig. 14 is used to minimize the distance between the computed and reference (flux/current) curve in case (2) of base speed $(n=n b)$ by changing and finding the optimal vector $x$ of “conduction angle” (Fig. 15).

TABLE II

PARAMETERS CONSTRAINTS

\begin{tabular}{c}
$-5<\theta_{\text {on }}<10$ (Degrees) \\
$35<\theta_{\text {off }}<50$ (Degrees) \\
$\theta_{\text {on }}+\theta_{\text {off }}<50$ (Degrees) \\
$\theta_{0}=(15,50)$ (Degrees) \\
\hline
\end{tabular}




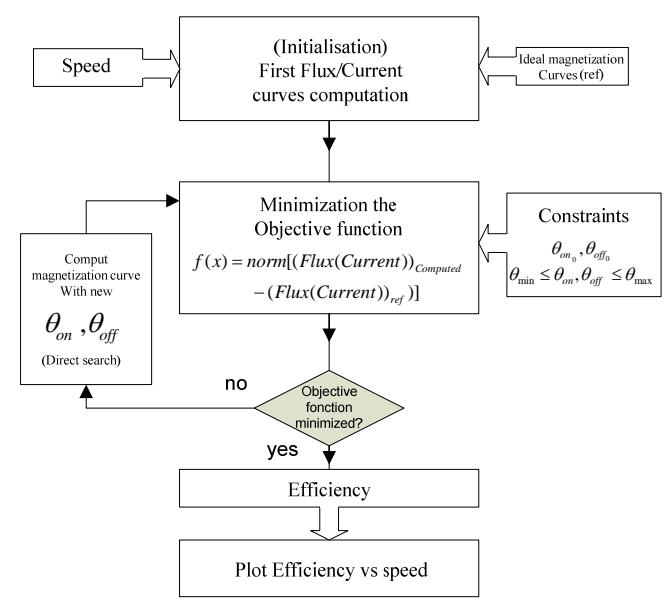

Fig. 14. Flowchart for the optimization method

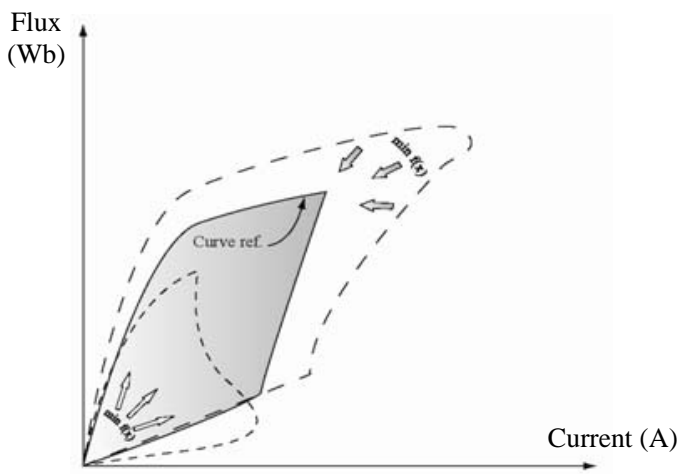

Fig. 15. Illustration of optimizing flux/current curves

Direct search is a method for solving optimization problems that does not require any information about the gradient of the objective function. Unlike more traditional optimization methods that use information about the gradient or higher derivatives to search for an optimal point, a direct search algorithm searches a set of points around the current point, looking for one where the value of the objective function (7) is lower than the value at the current point [18]. The structure of objective function is:

$f(x)=\operatorname{norm}($ Flux - Flux $\left._{\text {ref }}\right)+$ norm (Current - Current $\left._{\text {ref }}\right)(7)$

Fig. 16 shows the objective function value of the best point at each iteration. Fig. 17 shows optimized curves simulation for $n=500 \mathrm{rpm}$. The Objective function values improve rapidly at the early iterations and then level off as they approach the optimal angle conduction value (Fig. 18).

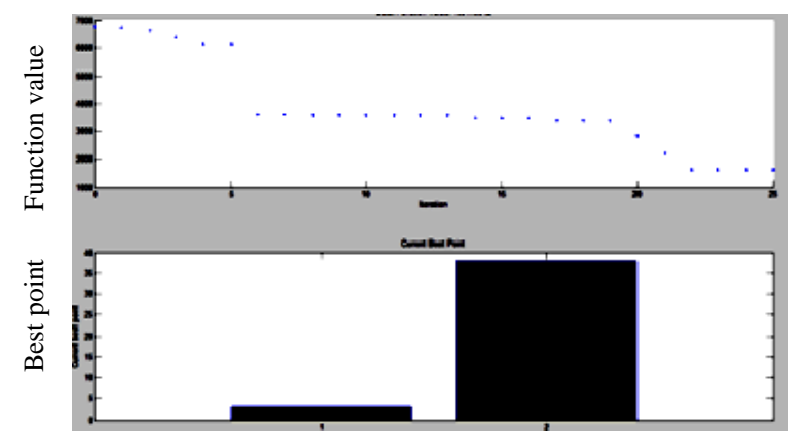

Fig. 16. Objective function values and the best point at each iteration

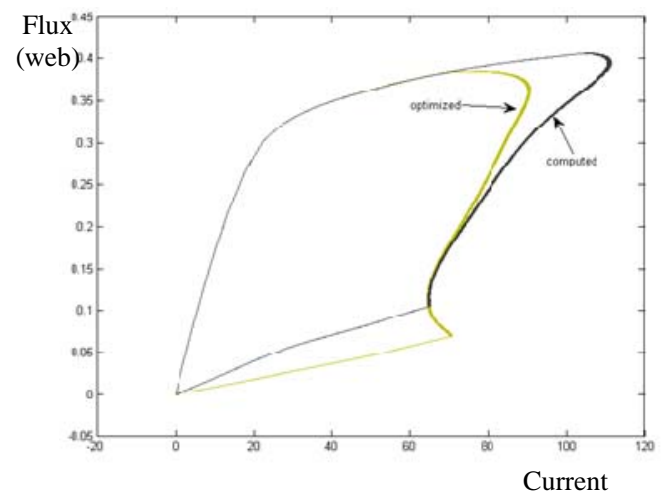

Fig. 17. Origin and optimized flux/current curves at n=500 rpm

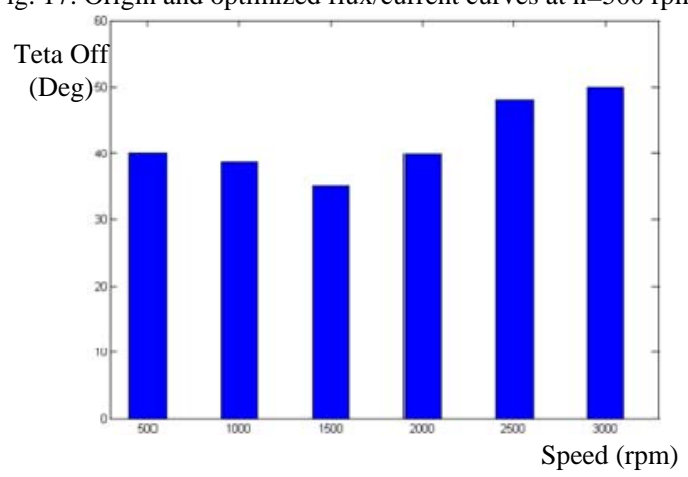

Fig. 18. Optimal conduction angle versus speed

The SRG transfers power in pulse, suggesting the need of an end capacitor to control the load voltage. The time variation of the capacitor used to continuously supply the load is represented in Fig. 19. It can be noticed that the energy stored in the magnetic field of excited phase flows to the end capacitor and to the load when the correspondent diode is conducting [1][19].

The efficiency is calculated by the following equation:

$$
\eta=\frac{P_{o}}{P_{e}+P_{m}} \times 100[\%]
$$

Where $P_{m}, P_{e}$ and $P_{o}$ are the mechanical input power, the electric excitation power and the output power, respectively.

Fig. 20 shows the variations of the efficiency with the rotational speed for optimized and reference conduction angles. The dashed curve shows the reference efficiency and the solid curve the optimized efficiency. This figure reveals that the efficiency of the $6 / 4$ SRG is about $80 \%$ in the wide region of the rotational speed.

\section{CONCLUSIONS}

This paper has examined the problem of choosing the conduction angles for accomplishing optimal control of SRG. The optimal angles are specified by a simple method based on the optimization of conduction angle to approach the ideal (flux/current) base speed curve, and maximize energy conversion. The direct relationship between the losses and rms phase current in the SRG determine the maximum efficiency. Simulation results are presented. 


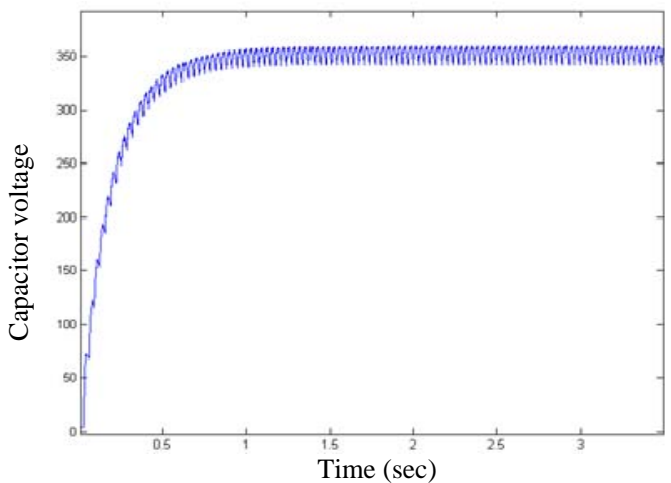

Fig. 19. Capacitor voltage

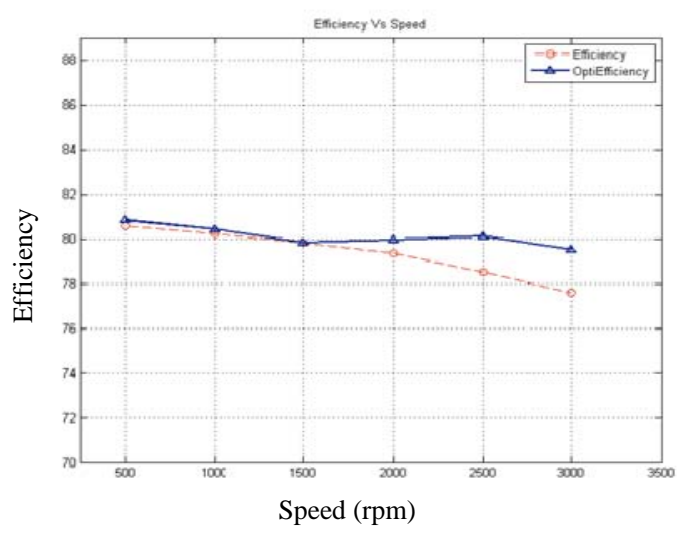

Fig. 20. Efficiency with optimized conduction angles

\section{APPENDIX}

$$
T_{e}, T_{a v}
$$

Electromagnetic and

average torque respectively

$$
W_{c}, W_{e}, W_{\text {mec }}
$$

Co-energy, Magnetic energy and Mechanical energy respectively

$$
\theta_{\text {on }}, \theta_{\text {off }}, \theta_{r}
$$

Turn-on, turn-off and rotor angle respectively

$$
R, L \quad \text { Phase }
$$

resistance and phase inductance respectively

$$
\psi, i
$$

Flux and phase

current respectively

$m$

Number

of

phases

$N_{r}$

rotor poles

$V_{d c}, E$

back EMF respectively

$\omega$

Angular speed

[4] Flux-2D, software package for resolution by FEM, Cedrat Zirst, 38 240 Meylan, France.

[5] D. A. Torrey, "Switched Reluctance Generators and Their Control", IEEE Trans. Ind. Electron., vol. 49, No 1, pp. 3 - 14. Feb. 2002.

[6] K. Buehring, L.L. Freris, "Control policies for wind-energy conversion systems”, IEE Proc.C, Sept 1981,vol. 128, No. 5, pp. 153-261.

[7] E. A. Bossanyi, "Options for variable speed operation of horizontal axis wind turbine generators”, Report prepared for Dept of Energy by Wind Energy Group Alpha House, Westmount Centre.

[8] P. I. Lawrenson, "Variable speed switched reluctance motors", IEE Proc. B, July 1980, vol. 127, No 4, pp 253.265.

[9] T. J. Miller, "Converter Volt ampere Requirement of the Switched Reluctance Motor Drive”, IEEE Trans. Ind. Applic., vol. IA-21, No. 5, pp 1136-1 144, Sept/Oct 1985.

[10] W F. Ray, R. M. Davis, "Inverter drive for doubly salient reluctance motor: its fundamental behaviour linear analysis and implications”, Electrical power applications, December 1979, vol. 2, No. 6, pp 185193.

[11] R. M Davis, W. F. Ray et al. "Inverter drive for switched reluctance motor: circuit and components ratings", IEE Proc B, March 1981, vol. 128, No. 2, pp 126-136.

[12] M. Ilk-Spong et al," "Feedback Linearising Control of Switched Reluctance Motor”, IEEE Trans. Aut., May 1987, vol. AC-32, No. 5 pp. 371-379.

[13] C. Johnson, R. Smith, "Dynamics of wind generators on electric utility network”, July 1976, IEEE Trans. Ind. Applic., vol. AES- I2, No 4, pp 483-493.

[14] S. Vukosavic, V. Stefanovic, "SRM inverter topologies a comparative evaluation”, IEEE Trans. Ind. Applic., vol. IA-27, No 6, Novernber-December, pp 1034-1 047.

[15] B. Bose, T.J.E. Miller,”Microcomputer control of switched reluctance motor”, IEEE trans. Ind. Applic., vol. IA-22,No 4, pp 708-715, July / August 1986.

[16] Leithead W, "Wind turbine control system modelling and design", report prepared for Dpt. of energy by Industrial Control Unit, University of Strathclyde, Glasgow. IJK. 1988.

[17] R.Cardenas, "Switched Reluctance Generators for wind energy application”, Power Electronics Specialists Conference, 1995. PESC '95 Record. 26th Annual IEEE, vol. 1, 18-22 June 1995, pp. $559-$ 564.

[18] MATLAB, language of technical computing, R2008b, 1994-2009, The MathWorks, Inc.

[19] J. Faiz and R. Fazai, "Modeling of losses in switched reluctance Generators”, 2nd International Conference on Technical and Physical Problems in Power Engineering (TPE-2004), September 2004, Tabriz, Iran.

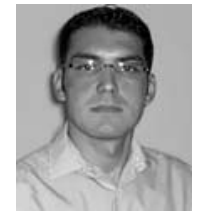

R. Rebbah: (1979) received the M.S. degrees from Mentouri University of Constantine. He is currently Assistant researcher in the Department of Electrical Engineering at the University of Constantine, Algeria, engaged in research. His interests are in the areas of simulation and motor optimization, energy conversion analysis, and modeling of power converters. He has worked toward the development of the switched reluctance generator controls and geometries.

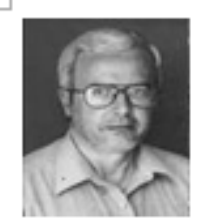

A. Bentounsi : (1953) After receiving its "doctorateengineer" in Paris 6, France, in 1980, he joined the University of Constantine, Algeria, in 1984, as an Associate Professor. Since 1995, he is working on his Ph.D. dissertation in collaboration with the Cegely Lab. of Ecole Centrale Lyon, France. He was the cofounder of the Laboratoire d'Electrotechnique de Constantine (LEC), Algeria, in 1999. His current research interests are CAD \& failure analysis of the electrical machines and renewable energy conversion.

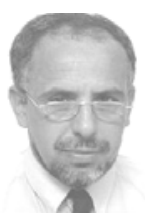

H. Benalla: (1957) He received the B.S., M.S., and Doctorate Engineer degrees in power electronics, from the National Polytechnic Institute of Toulouse, France, respectively in 1981, 1984. In 1995, he received the Ph.D. degree in Electrical Engineering from University of Jussieu-Paris VI, France. Since 1996, he is with the department of Electrotechnics, at Constantine University Algeria, as a Professor. His current research field includes Active Power Filters, PWM Inverters, Electric Machines, and AC Drives 